Clariana Rodrigues Soares

\title{
INFLUÊNCIA DOS HORMÔNIOS SEXUAIS FEMININOS SOBRE A INFLAMAÇÃO ALÉRGICA PULMONAR EM MODELO MURINO DE ASMA CRÔNICA
}

Dissertação apresentada ao Departamento de Farmacologia do Instituto de Ciências Biomédicas da Universidade de São Paulo, para obtenção do Título de Mestre em Ciências.

Área de concentração: Farmacologia

Orientador: Prof. Dr. Wothan Tavares de Lima 


\section{Resumo}

SOARES-RODRIGUES, C. Influência dos hormônios sexuais femininos sobre a inflamação alérgica pulmonar em modelo murino de asma crônica. 2010. 102 f. Dissertação (Mestrado em Farmacologia) - Instituto de Ciências Biomédicas, Universidade de São Paulo, São Paulo, 2010.

Avaliamos a influência dos hormônios sexuais sobre a inflamação alérgica pulmonar em modelo experimental de asma crônica. Grupos: Basal, animais não manipulados; OVx (ovariectomizados) e Sham-OVx/alérgico (falsamente operados), sensibilizados 7 dias após a ovariectomia e desafiados com OVA a partir do 21ㅇ dia; $\mathrm{OVx}+\mathrm{P} /$ alérgico, tratados com progesterona antes da sensibilização ou $\mathrm{OVx}+\mathrm{E} /$ alérgico tratados com estradiol antes da sensibilização e dos desafios, seguindo o protocolo dos animais OVx. Nossos resultados mostraram que a ovariectomia reduz a migração celular para o pulmão no grupo OVx em relação ao grupo Sham-OVx/alérgico. O tratamento com estradiol aumentou o número total de células no grupo $\mathrm{OVx}+\mathrm{E} /$ alérgico, enquanto o tratamento com progesterona no grupo $\mathrm{OVx}+\mathrm{P} / \mathrm{alérgico}$ reduziu a migração celular para 0 pulmão. Em relação a quantificação de muco nas vias aéreas, observamos redução de muco e colágeno no grupo OVx em relação ao grupo Sham-OVx/alérgico. Nos animais do grupo $\mathrm{OVx}+\mathrm{P} /$ alérgico observou-se aumento na produção de colágeno em relação ao gupo sem tratamento.

Palavras-chave: Inflamação pulmonar. Asma. Estrógeno. Progesterona. Camundongos. 


\begin{abstract}
SOARES-RODRIGUES, C. Influence of the female sexual hormones about the pulmonary allergic inflammation in model murino of chronic asthma. 2010. 102 f. Dissertation Master degree (Pharmacology) - Institute of Biomedical Sciences, University of Sao Paulo, Sao Paulo, 2010.

we evaluated the influence of female sex hormones on the pulmonary alergic asthma in a experimental chronic asthma model.Groups: Basal, (non-manipulated animals), Ovx (Ovariectomized) and Sham- Ovx/ allergic ( animals subjected to similar manipulations except for the ovaries removal) sensitized 7 days after ovarietcomy and challenged with OVA after the 21st Day, OVX+P/allergic, treated with progesterone $(200 \mu \mathrm{g} / \mathrm{Kg}) 24 \mathrm{~h}$ before sensitization or OVx+E/allergic treated with estradiol $(300 \mu \mathrm{g} / \mathrm{Kg}) 4 \mathrm{~h}$ before sensitization and the realized challenges, according to the protocol of Ovx animal. Our results showed that the ovarietomy (Ovx) reduces cell migration towards the lungs in OVx groups when compared to the Sham-OVx/allergic group. The treatment with estradiol increased the total number of cells in the Ovx+E/alleric group, while the treatment with progesterone in the $\mathrm{OVx}+\mathrm{P} /$ allergic group reduced cell migration towards the lung. About the quantification of mucus in the airways, we observed the reduction of mucus and collagen in the OVx group comparing to the non-treated group.
\end{abstract}

Key words: Pulmonary inflammation. Asthma. Estrogen. Progesterone. Mice. 


\section{INTRODUÇÃO}

Dentre as doenças pulmonares obstrutivas que afetam um grande contingente de pessoas no mundo, a asma ocupa lugar de destaque. De acordo com a Organização Mundial de Saúde atualmente 300 milhões de pessoas sofrem desta doença. No Brasil, as estatísticas indicam que ocorreram 879.877 internações por asma apenas no mês de julho de 2009, sendo 50.000 apenas no estado de São Paulo (DATASUS, 2009). A conseqüência social da asma é agravada pelos altos valores dispendidos com internações hospitalares, o grau de absenteísmo na escola, no trabalho e na piora da qualidade de vida dos pacientes asmáticos (ROCHLITZER et al., 2006). Com respeito aos hormônios sexuais femininos (HSF), existem diversos fatores indicando que sua oscilação está envolvida com a piora do quadro asmático (TANG, 2001; REDMOND et al., 2004; STANFORD et al., 2006).

Observa-se na asma a presença de células inflamatórias no pulmão, citocinas, quimiocinas, aumento da expressão de moléculas de adesão, lesão epitelial, hiperreatividade brônquica e remodelamento das vias aéreas. Dentre as células envolvidas na inflamação destacam-se mastócitos, eosinófilos, linfócitos $T$, macrófagos, neutrófilos. Em conjunto, essas células liberam mediadores inflamatórios que contribuem para a manutenção e desenvolvimento da doença. Células estruturais das vias aéreas como as células da musculatura lisa, fibroblastos e epiteliais também produzem mediadores inflamatórios e exercem importante papel na persistência da inflamação (MEHROTRA et al., 2009). Na vigência da inflamação crônica pode haver o aparecimento da hiperreatividade da musculatura lisa. Tal fenômeno leva a episódios recorrentes de falta de ar, sibilos, respiração ofegante e tosse, principalmente nos períodos da manhã e da noite (MARIM, 1997).

Frank et al., (1931), foram os primeiros a reconhecer a interação da exacerbação dos sintomas da asma com a variação dos HSF observada no ciclo sexual feminino. Estes autores observaram aumento na variabilidade do pico de fluxo expiratório (PFE) no período que antecede a menstruação (2 a 3 dias). A partir desses estudos definiu-se asma pré-menstrual como sendo as disfunções pulmonares detectadas no período que antecede a menstruação. Estudos subseqüentes mostraram a existência de um subgrupo de mulheres asmáticas (30\% 
a 40\%) cuja função pulmonar se deteriora durante o período menstrual (SKOBELLOF, 1996; CHHABRA et al., 2005). É importante destacar que a asma não ocorre somente com mais freqüência em mulheres adultas em idade reprodutiva, mas também mulheres asmáticas experienciam a forma mais grave desta doença. Visitas ao setor de emergência hospitalar com subsequentes hospitalizações, assim como admissão em unidades de terapia intensiva, por agravamento dos sintomas da asma, são mais comuns entre mulheres adultas quando comparadas com homens (ROWE et al., 2009; RAO et al., 2003). Alguns estudos demonstram que mulheres asmáticas possuem maior dificuldade em controlar os sintomas da asma (TEMPRANO AND MANNINO, 2009) e, além disso, experienciam longos períodos de hospitalização (ALMARRI, 2006; SKOBELOFF et al., 1992; GEHLBACH et al., 2002; LIN AND REHMAN, 1995). Um estudo realizado com mulheres asmáticas entre 21 e 48 anos com ciclo menstrual regular revelou que $57 \%$ das mulheres apresentaram piora dos sintomas asmáticos e $14 \%$ destas mulheres apresentam piora do pico de fluxo expiratório no final da fase luteal (MURPHY AND GIBSON, 2008). Apesar de os estudos indicarem o envolvimento do estradiol e da progesterona na indução/modulação de alterações no volume expiratório forçado (FEV1) em pacientes asmáticas, os dados existentes acerca dos mecanismos subjacentes das alterações da asma em mulheres e que estejam relacionados à oscilação dos hormônios sexuais femininos são controvertidos. Vários estudos clínicos levam em consideração a relação gênero-idade e relatam que na infância a asma é mais freqüente em meninos (ALMQVIST et al., 2008). Todavia, na puberdade a doença torna se mais comum em garotas; e por volta da quinta ou sexta década de vida, ou seja, na pós- menopausa, a prevalência torna- se maior em mulheres (CANBERRA, 2003). No entanto, outros estudos relatam baixa incidência de asma em mulheres na pós-menopausa quando comparadas a mulheres jovens. Em contrapartida, mulheres na pós-menopausa sob terapia de reposição hormonal evidenciam maior incidência da doença (LANGE et al., 2001; TROISI et al., 1995; BARR et al., 2004 GOMEZ et al., 2006; SIROUX et al., 2004).

Do ponto de vista da indução da asma, indivíduos sensibilizados, ou seja, quando em contato com o antígeno, desencadeiam a resposta alérgica aguda na qual os mastócitos e a imunoglobulina $\mathrm{E}(\mathrm{IgE})$ parecem ser fundamentais (GALLI et al., 2008). Nessas condições observa-se reação asmática aguda a qual se caracteriza por broncoconstrição, aumento da permeabilidade vascular, edema e 
secreção de muco (GALLI et al., 2007). Nesse contexto criam-se condições para o desenvolvimento da resposta inflamatória pulmonar onde os eventos pulmonares contribuem para o quadro crônico da asma bem como para suas repercussões funcionais tais como hiperreatividade brônquica e remodelamento (CARRILLO DIAZ et al., 2006).

Como mencionado, a fase aguda da asma precede os eventos observados na fase crônica. Para que o organismo seja sensibilizado é necessário o seu contato prévio com o agente imunogênico. Admite-se que após a inalação do alérgeno iniciase o processo de sensibilização. Fatores genéticos e ambientais podem favorecer a permeabilidade aos alérgenos e, conseqüentemente, o desenvolvimento da resposta Th2. Muitos alérgenos são proteínas, alguns são lipídios ou carboidratos e outros podem ainda ser proteases como, por exemplo, a poeira caseira. Estas proteases podem reduzir diretamente a função da barreira epitelial e ainda facilitar a entrada do alérgeno no tecido.

O processo de sensibilização se inicia com o antígeno sendo processado por macrófagos e outras células apresentadoras de antígenos, como as células dendríticas. Uma vez processados os fragmentos dos antígenos são apresentados aos linfócitos $T$ que auxiliam os linfócitos B a produzir imunoglobulinas. Estas, por sua vez, ligam-se aos receptores presentes em mastócitos e basófilos. A ligação do alérgeno à lgE presente em mastócitos e basófilos leva a liberação de mediadores inflamatórios (YING et al., 2006). Entre os efeitos dos mediadores inflamatórios observados estão à constrição da musculatura das vias aéreas, dilatação de vasos sanguíneos, o aumento da permeabilidade microvascular, estimulação das terminações nervosas sensoriais e secreção de muco na vias aéreas a qual ocupam lugar de destaque (OKAYAMA et al., 2007). Portanto a reação de fase aguda, ou seja, que ocorre minutos após a exposição ao alérgeno reflete os mediadores secretados pelos mastócitos no local afetado. Neste cenário a ação dos mastócitos contribui, portanto, com a indução da fase tardia visto aumentar o recrutamento de leucócitos (GALLI et al., 2008). Neste cenário, os mediadores inflamatórios liberados/gerados pelos mastócitos ativados pela ligação do antígeno com moléculas de $\operatorname{lgE}$, exercem efeitos importantes na indução do recrutamento de células inflamatórias para o pulmão em período mais tardios (YING et al., 2006).

A reação de fase tardia ocorre, aproximadamente entre 6 e 9h após a exposição ao alérgeno e reflete as ações de células da resposta imune adaptativa 
(linfócitos Th1, linfócitos Th2) (KAY, 2001) e inata (neutrófilos, monócitos, eosinófilos e basófilos) que foram recrutadas da circulação, assim como a secreção de mediadores inflamatórios residentes nos tecidos. Numa reação tardia, os leucócitos recrutados são as células $T$ as quais contribuem com alterações das citocinas no sítio afetado, granulócitos (eosinófilos, neutrófilos e basófilos) e monócitos (OKAYAMA et al., 2007). Geralmente esta fase se resolve espontaneamente, todavia, os mecanismos responsáveis por isso ainda são desconhecidos. Galli et al., (2008) sugerem que a resposta tardia está associada ao acúmulo de eosinófilos no pulmão; enquanto Metzger et al. (1986) observaram não só eosinófilos como também neutrófilos durante a fase tardia da asma.

Quando a exposição ao alérgeno é contínua e muita célula da imunidade inata e adaptativa vindas da circulação são encontradas nos tecidos, a reação inflamatória torna-se crônica. Sendo assim, a inflamação pulmonar persistente está relacionada com as alterações estruturais celulares nos locais afetados. Sabe-se que a inflamação persistente em pacientes com asma crônica envolve várias camadas das paredes das vias aéreas que estão associadas com: alterações no epitélio, incluindo o aumento das células de Goblet; aumento de citocinas e quimiocinas produzidas pelas células epiteliais, assim como injúria epitelial; inflamação da submucosa; aumento da deposição de proteínas da matrix extracelular na lâmina reticular; alterações dos fibrobastos, miofibroblastos e neovascularização; hiperplasia e hipetrofia das células musculares lisas (SCHLEIMER et al., 2007; DOHERTY e BROIDE, 2007; MAUAD et al., 2007).

As alterações estruturais da fase crônica da asma são observadas tanto nas vias aéreas superiores quanto nas inferiores (ARVIDSSON et al., 2007). É notável que a obstrução crônica das vias respiratórias possa ser mais grave e prolongada que a observada na fase aguda da doença. Sugere-se que este evento seja em decorrência do aumento das células secretoras de muco e da perda de cílios (REINHARDT et al., 2005). Em análises histopatológicas de pulmão de pacientes asmáticos, a submucosa apresenta-se infiltrada de linfócitos, macrógafos, eosinófilos e nota-se aumento da permeabilidade vascular. O epitélio brônquico se apresenta particularmente danificado e contêm infiltrados de células inflamatórias, especialmente linfócitos (GINA, 2009). Ainda, ocorre descamação com perda de cílios e a deposição de colágeno torna a membrana basal enrijecida (REINHARDT et al., 2005). Um aspecto importantes da fase crônica é o aumento da secreção de 
muco mediada pelo aumento das células de Goblets, glândulas secretoras de muco, além da hipertrofia da muscultarura lisa (BOUSQUET et al., 2000). Há também aumento de células de Goblet, de glândulas secretoras de muco e de células da musculatura lisa (SHIMURA et al., 1996).

Ressalte-se que, além de eosinófilos, neutrófilos também são considerados células importantes na indução/piora da asma (WARD et al., 2002; HAMID et al., 2003; KHOR et al., 2007) e ainda, considerando que o desenvolvimento da asma envolve a sensibilização do organismo, as células envolvidas na resposta imune adquirida assim como os linfócitos, células apresentadoras de antígeno e o complexo principal de histocompatibilidade devem ser considerados importantes (GALLI et al., 2008). Mosmann e Coffman (1989) descreveram subpopulações de linfócitos auxiliares caracterizados pelo padrão de produção de citocinas. Nesta situação, linfócitos Th1 geram citocinas cujas ações são importantes para defesa contra fungos e vírus (componente da imunidade celular) em contraste aos Th2, os quais liberam citocinas com participação na inflamação alérgica (BARNES, 2008). Considera-se, portanto, que a asma é uma doença com perfil tipo Th2. No contexto da asma, a produção de anticorpos depende de linfócitos Th2, que secretam IL-4 e esta estimula a produção de lgE pelos linfócitos B (AKDIS et al., 2005). De forma contrária, em situações onde o linfócito envolvido são os Th1, a secreção de INF- $\gamma$ por estas células é predominante, não havendo sinalização para produção de $\lg E$ (CALVANI et al., 2005). Esses eventos são decorrentes da apresentação do antígeno por meio das células dendríticas as quais estão envolvidas na iniciação e amplificação da resposta imune, além de influenciarem a diferenciação da resposta em Th1 e Th2 (HOLGATE, 2008). Logo, as características das citocinas derivadas dos linfócitos Th1 e Th2 são inibitórias para a diferenciação e função dos fenótipos Th1 ou Th2, ou seja, as citocinas Th1 inibem os produtos dos linfócitos Th2 e viceversa (MAGNAN et al., 2000). Assim, o IFN- $\gamma$ inibe a proliferação de células Th2 e a interleucina 10 (IL-10) inibe as citocinas sintetizadas pelos linfócitos Th1. Este "crossregulation" pode explicar o direcionamento da resposta para o perfil Th1 ou Th2 durante muitas infecções em camundongos e seres humanos. Segundo Caron et al., (2001), a exposição de células dendríticas à histamina proveniente de mastócitos promove maturação e diferenciação de linfócitos $T$ naive em linfócitos Th2. Havendo predominância de ativação de linfócitos Th2 há direcionamento da resposta imune para o padrão de citocinas tipicamente alérgico (IL-4 e IL-13). Tais 
citocinas participam da estimulação e coordenação da secreção de imunoglobulinas e contribuem, portanto, para o desencadeamento de quadros de alergia bem com para o desencadeamento da asma (NGOC et al., 2005).

O direcionamento da resposta imune para o perfil Th2 é um componente importante do processo alérgico das vias aéreas. Nesse sentido, a hipótese da higiene relata que em pessoas expostas a parasitas e a outros microorganismos, na infância, o resultado do fenótipo dominante é o Th1e podem, portanto, ser menos suscetíveis a asma alérgica. Nos ambientes onde a higiene é melhor, há menos exposição a agentes infecciosos, a resposta Th1 é menor e a resposta Th2 pode se tornar mais prevalente (VAN OOSTERHOUT et al., 2005). Todavia, uma vez que as células Th1 bloqueiam a função das células Th2, é possível que o rebalanço das células Th1/Th2 podem beneficiar alguns asmáticos (WOODFOLK, 2006).

As citocinas Th2 favorecem a produção de anticorpos, particularmente a lgE e, ainda, contribuem com a proliferação de eosinófilos. Nesse contexto, os linfócitos Th2 produzem diversas interleucinas (IL) como, por exemplo, a IL- 4, IL-5, IL-10 e IL13 que são necessárias ao desenvolvimento da resposta alérgica (MOSMANN et al., 1996).

Do ponto de vista da participação dos mediadores inflamatórios, é bem estabelecido o envolvimento de citocinas no controle imunológico da asma (SHANNON et al., 2008). Nesse sentido, a IL-4 medeia a síntese lgE (MONTERO, 2006), estimula a produção de muco, fibroblastos e o remodelamento das vias aéreas (KIPS et al., 2000).

A IL-5 favorece o tráfego de eosinófilos da medula óssea para as vias aéreas. Em resposta a IL-5, macrófagos, eosinófilos e neutrófilos circulantes no leito vascular do tecido pulmonar, interagem com moléculas de adesão no tecido perivascular e peribrônquico e migram para vias aéreas (COHN et al., 2001).

A IL-13 induz a fibrose pulmonar e, assim como a IL-4, estimula a secreção de muco além de contribuir para a perpetuação da lesão tecidual (MONTERO, 2006). É interessante notar que ratos tratados com anticorpo monoclonal anti-IL-13 reduziram ou não desenvolveram a hiperreatividade das vias aéreas, paralelamente ao desenvolvimento da fibrose subepitelial e progressão da inflamação terem diminuidos. Além disso, o tratamento dos animais reverteu a hiperplasia das glândulas produtoras de muco. Estes dados demonstram que anticorpos 
monoclonais anti IL-13 podem ser úteis no controle da doença durante exposições repetidas ao alérgeno (YANG et al., 2005).

Outra citocina relevante na asma é o TNF. Esta citocina exerce um amplo efeito no contexto da resposta inflamatória. Nesse contexto sabe- se que o TNF possui efeitos pró-inflamatórios tais como recrutamento de leucócitos por meio de "upregulation" de moléculas de adesão e a interage com a síntese de citocinas e quimiocinas. Além disso, é um potente estimulante de fibroblastos e, portanto, pode desempenhar uma importante função no remodelamento das vias aéreas. O TNF pode mediar o inicio da inflamação crônica, ativando a secreção de citocinas de uma variedade de células das vias aéreas (BARNES, 2008). O potencial envolvimento do TNF na asma pode também ser sugerido pelo fato de está citocina estar presente em secreções, no líquido de lavado broncoalveolar e em biópsias de asmáticos (KIPS, 2001).

Com respeito ao IFN- $\gamma$, este é produzido por células Th1 e exerce efeito inibitório sobre as células Th2 e por causa disto pode suprimir as respostas alérgicas (ROMAGNANI, 2006). A síntese de IFN- $\gamma$ é induzida pela IL-12 por meio das células apresentadoras de antígenos, como células dendríticas e macrófagos em resposta a agentes do microambiente como vírus, por exemplo (TORRES et al., 2004). As células apresentadoras de antígenos fazem o primeiro contato das células $T$ naive com o antígeno, assim a produção de IL-12 é necessária para direcionar a resposta imune para o perfil Th1 (WENNER et al., 1996). Vale lembrar que pacientes asmáticos submetidos à aerossolterapia contendo IFN- $\gamma$ têm redução de eosinófilos no LBA (MOYNIHAN et al., 2008). Ainda a administração de anticorpos anti- IFN- $\gamma$ suprime a hiperreatividade das vias aéreas. Foi demonstrado que num desafio crônico com alérgeno, houve produção de linfócitos TCD4+ por IFN- $\gamma$ em linfonodos peribrônquicos (KUMAR et al., 2006) e o tratamento dos animais com anti- IFN- $\gamma$ diminuiu a produção de células TCD4+. A transferência de linfócitos TCD4+ de ratos alérgicos para ratos não manipulados desencadeia a hiperreatividade das vias aéreas após estimulo com metacolina, explicando a capacidade do anti-IFN- $\gamma$ em inibir a hiperreatividade das vias (MOYNIHAN et al., 2008).

O recrutamento de leucócitos circulantes para tecidos é regulado também pela interação leucócitos-endotélio e várias famílias de moléculas de adesão (LEY, 2003). A migração de leucócitos para o tecido pulmonar depende das moléculas de 
adesão (CAMs), L-selectina e da molécula de adesão intercelular (ICAM)-1, ambas expressas na superfície celular e no endotélio (TANG et al., 2001). Os leucócitos circulantes interagem com o endotélio vascular por meio de rolamento ao longo da parede dos vasos. O processo de rolamento de leucócitos começa minutos após a sensibilização, alcançando um pico entre 20 a 40 minutos, permanecendo constante na circulação por pelo menos até 2h (BUTCHER, 1993).

As moléculas de adesão são sinalizadoras e participam da regulação da inflamação e da resposta imunológica como ocorre na asma (SPERTINI et al., 1991), desempenhando um papel relevante na mobilização celular. Podem, no pulmão, regular o extravasamento e migração de leucócitos para o interstício, ativar células e rete-las no tecido (WOODSIDE et al., 2008). Além disso, as moléculas de adesão medeiam às adesões celulares ao epitélio e ao endotélio, participam do recrutamento e migração de células inflamatórias dos vasos sangüíneos até o local da inflamação (ULBICH et al., 2003). As selectinas estão envolvidas com o tráfego de células do sistema imune inato, de linfócitos $T$ e plaquetas. (GRAVES et al., 1994). Este grupo de moléculas de adesão (selectinas) é composto por três proteínas que são diferentemente expressas em leucócitos (L-selectina), em plaquetas (P-selectina) e no endotélio vascular (E-selectina) (TEDDER et al.,1995). Em contraste com outras moléculas de adesão, a função das selectinas é restrita a interação dos leucócitos com o endotélio vascular (LEY, 2003).

A L-selectina é expressa em leucócitos do sangue periférico e medeia o rolamento destes na microcirculação (ARIFHODZIC et al., 2005). Em modelos experimentais, camundongos transgênicos deficientes em L-selectina reduzem a capacidade de migração dos leucócitos circulantes. A migração de linfócitos também pode ser regulada pela L-selectina, uma vez que a deficiência da expressão dessas moléculas resulta em um número aumentado de linfócitos residentes no baço além de uma maior tendência de migração celular para o baço, em camundongos "nockout" para a L-selectina (ARBONES et al., 1994). Por outro lado, apesar de alguns estudos afirmarem que a L-selectina é fundamental no processo da inflamação do pulmão e das vias aéreas, Lynne et al. (2001) evidenciaram que não há redução significante do influxo de leucócitos nas vias aéreas de camudongos deficientes de L-selectina, não obstante, a ausência da L-selectina tenha sido associada a redução seletiva de linfócitos TCD3+ no lavado broncoalveolar. Todavia, uma observação interessante é a de que a ausência da L-selectina em 
camundongos "nockout" contribui para a redução da hiperreatividade das vias aéreas. Esses dados podem estar relacionados com os linfócitos TCD3+ (TANG et al., 2001).

A E- selectina é sintetizada por células endoteliais e medeia a adesão de neutrófilos no endotélio vascular. Uma vez expressa, ela é direcionada à lisossomos para a degradação (SUBRAMANIAM et al.,1993) assim, outras moléculas de Eselectinas podem ser depositadas, havendo um aumento na expressão destas moléculas na membrana plasmática e, consequentemente, excesso de leucócitos recrutados (ROSSI et al., 2008), Sabe-se que o bloqueio de sua função pode diminuir o acúmulo de neutrófilos (WOODSIDE et al., 2008). Não obstante, a Eselectina também contribui com o processo inflamatório agudo das vias aéreas e com a obstrução das mesmas (NADI et al., 2007). De fato, tanto a E como a Pselectina estão envolvidas com a lesão pulmonar em modelos experimentais de injuria pulmonar em ratos (PITCHFORD et al., 2005).

Originalmente, a P-selectina foi purificada de plaquetas e mais tarde foi encontrada em células endoteliais; é expressa e armazenada em grânulos secretores (grânulos- $\alpha$ de plaquetas e de células endotelias) (MCEVER et al., 1989). A P-selectina mobilizada de grânulos a de plaquetas pode estar envolvida na fase inicial do rolamento de leucócitos, uma vez que o seu bloqueio reduz o transporte inicial de leucócitos nos vasos de mesentério (DORE et al., 1993).

Como mencionado, na asma, por conta do processo inflamatório recorrente, ocorrem lesões e reparações teciduais com subsequentes modificações estruturais na árvore brônquica, denominadas de remodelamento das vias aéreas. O repetido processo de reparo após a recorrente lesão tecidual inflamatória e as conseqüentes alterações na fisiologia das vias aéreas são potenciais indutores de remodelamento (BOUSQUET et al, 2004). Este é caracterizado por hiperplasia e hipertrofia das células de Goblet ou células ciliadas e das células do músculo liso, além da deposição de colágeno (KIM et al., 2006). Células estruturais, como as células epiteliais e células do músculo liso brônquico, participam da produção de mediadores e no desenvolvimento do remodelamento das vias aéreas na asma. Histologicamente, o remodelamento das vias aéreas é marcado por infiltrado de macrófagos e linfócitos, proliferação de fibroblastos, fibrose, destruição tecidual (MEHROTRA et al., 2009). O remodelamento da estrutura pulmonar é considerado característico de algumas alterações como, por exemplo, a fibrose subepitelial na 
asma. Essas mudanças no tecido pulmonar incluem alterações na matriz extracelular do pulmão, onde metaloproteinases estão envolvidas clivando proteínas estruturais como as fibras colágenas e da elastina (BOUSQUET et al., 2004; AMMINT, 2005).

Inseridas neste cenário estão as metaloproteinases (MMPs) as quais são enzimas proteolíticas derivadas das células do músculo liso ou de infiltrado de células inflamatórias. Podem modular a sinalização entre células do músculo liso e matriz extracelular (GREENLEE et al., 2007). As principais ações das MMPs estão relacionadas ao remodelamento dos componentes da matriz extracelularlas que forma uma estrutura de suporte para a parede das vias aéreas. A matriz extracelular é uma rede complexa de macromoléculas que formam uma estrutura de suporte para a parede das vias aéreas e é dinamicamente mantido pela ação das metaloproteinases as quais degradam a matriz extracelular, por meio da degradação do colágeno, da elastina e da fibronectina (BURGESS et al., 2008). A estrutura terciária das fibras de colágeno é perdida, uma vez que a desnaturação ocorre devido a atividade proteolítica de metaloproteinases (DAVIS et al., 2000). Os monômeros de colágeno que perdem a tripla hélice se ligam com alta afinidade pelas integrinas de colágeno (JOKINES et al., 2004). Isso pode explicar as respostas diferenciais que foram observadas em células do músculo liso vascular quando mantido em isoformas diferentes de colágeno tipo I (RAINES et al., 2000). De maneira interessante, a forma monomérica de colágeno tipo I aumenta a proliferação de células do músculo liso, mas deixa suas respostas proliferativas insensíveis ao tratamento por glicocorticóides (BONACCl et al., 2006). Também participam do processo de migração de células normais, malignas e inflamatórias, bem como induzindo a angioneogênese (LAMOOREAUX et al., 1998; TSUKIFUJI et al., 1999). As metaloproteinases produzem MMP-1,-2,-3,-9,-10,-12,e -14 (FODA et al., 1999). A transcrição do gene de metaloproteinases é induzida por fatores de crescimento e citocinas e o soro induz a expressão de MMP-2 e MMP-9 em células do músculo liso (GREENLEE et al., 2007).

A MMP-2 é produzida principalmente a partir de células mesenquimais (fibroblastos), ainda que células epidérmicas, endoteliais, macrófagos e neutrófilos possam produzi-la em pequenas quantidades (NGUYEN et al., 1998). Também é denominada colagenase tipo IV e, apesar de estar presente em níveis baixos fisiológicos em indivíduos normais (mantendo a homeostase do colágeno), quando 
ativada, pode deteriorar elastina insolúvel e destruir exageradamente o colágeno intersticial, além de participar da degradação da membrana basal do endotélio e de induzir a angiogênese (AGREN, 1998).

A MMP-9 é produzida por células inflamatórias ativadas (neutrófilos, eosinófilos e monócitos/macrófagos) e células epidérmicas (especificamente queratinócitos), sua presença sempre traduz uma situação patológica. Suas ações são direcionadas à degradação do colágeno intersticial, à reepitelização, ao desenvolvimento e amplificação de processos inflamatórios e à angiogênese (KOBAYASHI et al., 1999).

As múltiplas funções das metaloproteinases envolvem influencia na estrutura do músculo liso e no remodelamento das vias aéreas, ocasionando mudanças na mecânica pulmonar (BURGESS et al., 2008). Logo, a inibição das metaloproteinases está associada à redução da proliferação do músculo liso e ao aumento da proliferação de colágeno (HENDERSON et al. 2007).

Nas vias aéreas de asmáticos, o perfil de proteínas de matriz extracelular está alterado. Em análises histológicas de vias aéreas de indivíduos com e sem asma observa-se deposição de colágeno tipo I, III, e V, fibronectina, tenascina, versican e laminina ao passo que colágeno IV e a elastina consistentemente estão diminuídos (LAITINEN et al., 1997; ROBERTS e BURKE, 1998).

Acredita- se que um dos mecanismos de deposição de matriz extracelular é a desigualdade entre sua síntese e degradação. Durante a transmigração pela membrana basal, células inflamatórias tais como eosinófilos produzem e secretam metaloproteinase-9 (MMP-9) a qual é capaz de digerir colágeno tipo IV (OKADA et al., 1997). Todavia, a superprodução de inibidores tecidual de metaloproteinases-1 (TIMP-1), um inibidor de MMP-9, causa deposição de matriz extracelular e espessamento da membrana basal, impedindo a degradação de matriz extracelular. Contudo, a deposição de matriz extracelular consiste de colágeno tipo III e IV, laminina, tenacina e fibronectina (WILSON et al., 1996).

Freqüentemente, os componentes da matriz extracelular, tais como colágenos, são vistos como estruturas inertes, no entanto estudos recentes ilustram que estas proteínas têm a capacidade de alterar a função celular, influenciando o comportamentos celulares. É interessante notar que fragmentos de colágeno possuem propriedades tanto pró- inflamatórias quanto antiinflamatória (ZIAIE et al., 1999; THOMAS et al., 2007) e podem atrair quimiotaticamente neutrófilos para o 
pulmão, o que pode ser verificado tanto em estudos "in vitro" quanto "in vivo". Em uma exposição a longo prazo (12 semanas), fragmentos de colágeno instilados em vias aéreas de camundongos resultou em distensão alveolar, concentrações aumentadas de fator de crescimento endotelial (VEGF) e hipertrofia ventricular. Portanto, o desenvolvimento destas alterações estruturais sugere que fragmentos de colágeno podem exercer e regular a inflamação e remodelamento das vias aéreas (WEATHINGTON et al., 2006)

A destruição epitelial também é um dos aspectos importantes do remodelamento das vias aéreas, embora não seja incomum encontrá-la em biópsias de tecido das vias aéreas de indivíduos saudáveis. Todavia, em pacientes com asma, foi verificado que as células epiteliais sofrem mais apoptose do que as células de indivíduos normais. A destruição epitelial pode ser em parte conseqüência da inflamação ou do mecanismo de impacto causado pela broncoconstrição. Ainda pode também refletir a suscetibilidade do indivíduo. Alguns estudos sugerem alterações no fenótipo das células epiteliais de asmáticos e um aumento da capacidade destas células em produzir citocinas, quimiocinas e fatores de crescimento pró fibróticos (YING et al., 2006). Nesta situação, a destruição do epitélio colunar facilita a entrada de partículas infecciosas que penetram na parede das vias aéreas gerando uma resposta inflamatória com subseqüente dano epitelial (KNIGHT, 2002). Nesse contexto o substrato que é liberado pelas células epiteliais na borda da lesão pode migrar para reconstruir a camada de superfície lesionada (DEVALIA et al., 1993). Nestes eventos, além de contribuir para o acúmulo de matriz extracelular provisória, as células epiteliais das vias aéreas recebem apoio dos fibroblastos da parede brônquica subjacente que ativamente liberam citocinas capazes de estimular as funções das células epiteliais. Assim, a capacidade de reparo das células epiteliais é dependente não somente apenas de suas atividades e de sua interação com a matriz provisória, mas também com citocinas e outras células inflamatórias e parenquimais presentes nas vias aéreas, chamadas comumente de fibroblastos da parede brônquica (SACCO et al., 2004).

Um importante e consistente aspecto a ser considerado na asma é a produção excessiva de muco o qual bloqueia as vias aéreas periféricas e dificultam a expectoração. Em 1880 na Alemanha, estudos realizados em autópsias identificaram que rolhas de muco nas vias aéreas são umas das principais causa de morte na asma (HOGG, 1997). Estes achados foram repetidamente confirmados por 
outros trabalhos enquanto estudos recentes relatam que na asma fatal mais de $98 \%$ das vias aéreas se encontra obstruída por muco (KUYPER et al., 2003). Existem evidências de que as células de Goblets estão presentes nas vias aéreas periféricas de asmáticos enquanto numa condição normal não estão presentes (ORDONEZ et al., 2001). Além disso, na asma as glândulas submucosas são maiores em relação àquelas presentes numa via aérea normal e contém uma proporção maior de muco. Como resultado a secreção é anormal e com uma alta viscosidade do muco que junto com a proteína básica eosinofílica contribuem com a característica do muco tenaz e viscoso da asma (ROSE et al., 2006).

Como mencionado, estudos sugerem que a incidência, gravidade e o prognóstico da asma em mulheres podem ser afetados pela oscilação dos hormônios sexuais femininos seja no período menstrual ou na pós-menopausa. Dados obtidos em modelos experimentais de asma indicam que os hormônios sexuais podem interferir com o sistema imunológico, afetando as funções do timo, modulando as atividades dos fagócitos, linfócitos T, B e "natural killer". Estudos revelam que também afetam a produção de citocinas produzidas por linfócitos Th2 (HUGHES e CLARK, 2007). As células inflamatórias podem expressar receptores tanto para estrógeno quanto para progesterona. Em vias aéreas superiores, os mastócitos, por exemplo, expressam receptores para ambos os hormônios (ZHAO et al., 2001). Um estudo realizado com mulheres asmáticas revelou que o aumento dos níveis de progesterona no soro antes da menstruação, foi visto facilitar a desgranulação de mastócitos embora não tenha se observado aumento dos níveis de histamina (NAKASATO et al., 1999). A influência dos hormônios sexuais femininos sobre o número de células inflamatórias pode ser corroborada pela variabilidade cíclica nos níveis sanguineos de citocinas e mediadores envolvidos na inflamação. Os níveis de leucotrienos no soro, por exemplo, aumentam de forma considerável no período que antecede a menstruação em mulheres com asma prémenstrual. Em contrapartida este evento não ocorre em mulheres que não apresentam asma pré-mesntrual, onde nenhuma variação cíclica de histamina ou leucotrieno é observada (BRANNSTROM et al., 1999).

Diversos relatos documentam o agravamento da asma e a redução do pico de fluxo expiratório durante o período pré-menstrual (STANFORD et al., 2006). A broncoconstrição observada na asma neste período parece envolver a interação de hormônios sexuais femininos com a funcionalidade dos mastócitos (ROBINSON et 
al., 2004). Chabra (2005) demonstrou que os hormônios sexuais sensibilizam os receptores de adenosina presentes em mastócitos, fato que pode justificar a exacerbação da asma no período pré-menstrual. Além disso, as concentrações de mastócitos no soro de mulheres com asma pré- menstrual, durante o período que antecede a menstruação, são significantemente altas, favorecendo, portanto, o desenvolvimento de alergias (NAKASATO et al., 1999).

Existem dados associando as alterações pulmonares observadas na asma pré-menstrual à queda brusca dos níveis de estrógeno que ocorre no período pósovulatório e no período que antecede a menstruação (TAN, 2001; ENSOM et al., 2003; VRIEZE, 2003; CHHABRA, 2005). Por outro lado, dados sugerindo a existência de correlação entre asma pré-menstrual e aumento da relação estrógenoprogesterona circulante também estão disponíveis. Admite-se, nesta hipótese, que a progesterona exerça ação protetora, razão pela qual sua redução relativa poderia facilitar o desenvolvimento da asma em mulheres (BEYNON et al.,1988). Ainda, estudos realizados por Hellings et al. (2003) demonstraram aumento da reatividade das vias aéreas e da migração de células inflamatórias (em especial eosinófilos) para o tecido pulmonar após o tratamento de camundongos com progesterona na vigência da inflamação alérgica pulmonar (HELLINGS et al., 2003). É importante destacar que pacientes afetados pela asma pré-menstrual, em comparação com mulheres asmáticas que não apresentam exacerbação pré-menstrual, geralmente desenvolvem sintomas mais graves e, frequentemente, são mais hospitalizadas (BALZANO, 2001).

Dados obtidos em nosso laboratório utilizando modelo experimental de asma evidenciaram a influência dos hormônios sexuais femininos na inflamação alérgica pulmonar em diversos aspectos. O fio condutor dos nossos estudos foi investigar a participação dos hormônios sexuais femininos no recrutamento de células inflamatórias para o pulmão após a exposição aguda de alérgeno em animais ovariectomizados. Nesses estudos observamos que o estrógeno participa da modulação da mobilização de leucócitos circulantes e da medula óssea acarretando consequências para magnitude da inflamação alérgica pulmonar. $O$ modelo experimental que propusemos se constitui da sensibilização alérgica 1 ou 7 dias após a remoção dos ovários e desafio alérgico 14 dias após a sensibilização (grupos OVx/alérgico-1 e OVx/alérgico-7 respectivamente). Em síntese observamos no grupo OVx/alérgico-1 há potencialização da inflamação pulmonar. Por outro lado, 
detectamos redução da inflamação alérgica pulmonar no grupo OVx/alérgico-7. Tanto os efeitos observados no grupo OVx/alérgico-1 quanto aqueles do OVx/alérgico-7 parecem relacionar- se com a alteração na relação estrógeno/progesterona. Em estudos adicionais detectamos que o processo de sensibilização e a síntese de anticorpos anafiláticos, não foram afetados pela remoção dos ovários (LIGEIRO DE OLIVEIRA et al., 2004; RIFFO-VASQUEZ et al., 2007), mas de alguma forma os mastócitos, estão funcionalmente alterados (de OLIVEIRA et al., 2007). Ainda a redução dos níveis circulantes de estrógeno e de progesterona, no período de exposição dos animais ao agente sensibilizante associa-se às alterações na geração de IL-4, IL-10, TNF- $\alpha$ e IL-1 $\beta$, além de reduzir a expressão de moléculas de adesão (ICAM-1, E-selectina e Mac-1). O tratamento agudo dos animais com estradiol ou progesterona antes do desafio, pode ou não reverter tais interferências. Em síntese, a variação dos níveis circulantes dos hormônios sexuais femininos exerce efeito dual (aumento/redução) dos eventos que compõem a resposta inflamatória. Eventos como a desgranulação dos mastócitos, expressão de moléculas de adesão e a atividade funcional de fagócitos (pulmonares e de células da medula óssea), aumentam e posteriormente reduzem, na medida em que os níveis hormonais decaem em decorrência da remoção dos ovários e na vigência de um segundo estímulo inflamatório (desafio antigênico).

Em conjunto, nossos dados permitem sugerir a existência de um mecanismo de interferência seletiva dos hormônios sexuais femininos com o sistema imune no qual o período de tempo existente entre a remoção dos ovários e a sensibilização dos animais com o antígeno exerce importante papel modulador.

Riffo-Vasquez et al., (2007) mostraram que a remoção dos ovários 7 dias antes da sensibilização com OVA inibiu a eosinofilia pulmonar e os níveis de IL-5 no lavado broncoalveolar (LBA). Além do mais, a reatividade das vias aéreas mostrouse reduzida neste modelo. A proliferação de células do baço e a liberação de IL-5 foram atenuadas após a remoção dos ovários. Vale ressaltar que os animais OVx/alérgico, sensibilizados e tratados com estradiol apresentaram reversão parcial da redução de eosinófilos e dos níveis de IL-5. Enquanto o modulador de receptores de estrógeno (tamoxifeno) reduziu o número de eosinófilos no pulmão de camundongos com ovários intactos sensibilizados, reproduzindo o efeito da ovariectomia. Em conjunto esses dados sugerem um papel do estradiol no processo de sensibilização do organismo ao antígeno. Riffo-Vasquez et al. (2007) também 
mostraram que a remoção dos ovários 8 dias após a primeira sensibilização de OVA não altera a eosinofilia pulmonar nem a hiperreatividade das vias aéreas decorrente do desafio alérgico. Ainda, a remoção dos ovários 8 dias após o período de sensibilização induziu aumento significativo nos níveis de IL-5 no LBA. Vale lembrar que também neste modelo o estradiol reduziu parcialmente os eosinófilos presentes no pulmão de camundongos alérgicos OVx/alérgico, sugerindo um efeito antiinflamatório do estradiol durante a fase efetora da resposta imune.

Apesar de estudos, (desde 1940), demonstrarem consistentemente que mulheres asmáticas relatam agravamento dos sintomas da asma no período prémenstrual, as evidências a respeito Da influência dos hormônios sexuais femininos no contexto da asma ainda são contraditórias. Com o advento da terapia de reposição hormonal, estudos realizados relatam que o estrógeno em mulheres na pós- menopausa (induzida por meio de cirurgia ou normal) pode aumentar o risco do desenvolvimento da asma. Por outro lado, existem dados correlacionando a reposição de estrógeno tanto com a melhora como com a piora dos sintomas da asma (HAGGERTY et al., 2003; BAR et al., 2004; RIFFO-VASQUEZ et al., 2007).

Com base nesses dados é possível identificar uma complexa alteração dos HSF com o sistema imune. Todavia, estudos associando a ação dos hormônios sexuais femininos nas características da asma crônica ainda não estão bem estabelecidos, necessitando, portanto, de estudos adicionais.

\subsection{Justificativa}

Os estudos propostos nesse projeto têm como base avaliar a interferência dos hormônios sexuais femininos no desenvolvimento de algumas características da inflamação pulmonar em modelo murino de asma experimental crônica.

Os trabalhos conduzidos até o momento em nosso laboratório restringiram-se ao estudo dos componentes associados aos eventos agudos da resposta alérgica pulmonar. Não obstante, alguns dos aspectos da inflamação crônica que possam vir a ser controlados pelos hormônios sexuais femininos ainda não foram investigados.

Os dados existentes na literatura revelam que a oscilação dos hormônios sexuais femininos decorrentes do ciclo menstrual intensifica a sintomatologia da asma, notadamente a função pulmonar. Ainda, o estradiol aumenta a geração de algumas citocinas pró-inflamatórias pelos fagócitos pulmonares. Por outro lado, 
indicações acerca do efeito protetor dos hormônios sexuais femininos na asma também existem, indicando a subsistência de lacunas na compreensão dos efeitos dos hormônios sexuais femininos na asma. Inconsistências similares, a respeito do papel destes hormônios, também são descritas para mulheres na pós- menopausa e que estejam sob terapia de reposição hormonal. De fato, estudos demonstram que a redução dos hormônios sexuais femininos pode contribuir para a melhora ou piora dos sintomas asmáticos em mulheres na pós-menopausa. O tratamento com estradiol pode, portanto, ser condutor de alívio/piora do estado asmático.

Nesse contexto, considerando a asma como doença inflamatória crônica e a participação dos HSF nos eventos agudos da asma, investigaremos, neste estudo, as repercussões pulmonares da redução dos HSF no que tange a geração de mediadores inflamatórios, recrutamento celular pulmonar e remodelamento das vias aéreas. 


\section{CONCLUSÕES}

1. A redução da inflamação alérgica pulmonar crônica nos animais $O V x / a$ lérgico sugere que os hormônios sexuais femininos desempenham um papel modulador no curso da resposta inflamatória após múltiplas broncoprovocações;

2. Os hormônios sexuais femininos modulam notadamente o recrutamento de eosinófilos e neutrófilos e também interfere na migração de células da medula óssea para o sangue e deste para o pulmão no grupo OVx/alérgico;

4. A ausência dos hormônios sexuais femininos se associou a menor produção de citocinas como a IL-10 e a IL-5 em explante pulmonar no grupo OVx/alérgico;

5. Os hormônios sexuais femininos medeiam as alterações pulmonares envolvidas com o remodelamento como observado no grupo OVx/alérgico no qual a produção de muco e colágeno mostrou-se reduzida;

6. Neste modelo experimental de inflamação alérgica pulmonar crônica o estradiol parece exercer efeito pró-inflamatório;

7. A falha na migração celular para o pulmão observada no grupo $O V x+P / a l e ́ r g i c o$ está relacionada com os efeitos antiinflamatórios da progesterona;

9. A progesterona parece modular parte do remodelamento das vias aéreas de camundongos, uma vez que esta exacerbou a produção de colágeno no grupo de animais $\mathrm{OVx}+\mathrm{P} /$ alérgico;

10. O estradiol esta envolvido na produção de citocinas, aumentando a IL-5 e reduzindo a IL-4 em explante pulmonar no grupo OVx+E/alérgico. 


\section{Referências Bibliográficas}

AKDIS, M.; BLASER, K.; AKDIS, C. A. T regulatory cells in allergy: novel concepts in the pathogenesis, prevention, and treatment of allergic deseasis. J. Allergy Clin. Immunol., v. 116, n. 5, p. 961-8, 2005.

ALMARRI, M. R. Asthma hospitalizations in the state of Qatar: an epidemiologic overview. Ann. Allergy Asthma Immunol., v. 96, p. 311-315, 2006.

ALMQVIST, C.; WORM, M.; LEYNAERT, B. Impact of gender on asthma in childhood and adolescence: a GA2LEN review. Allergy, v. 63, p. 47-57, 2008.

ARBONES, M. L.; ORD, D. C.; LAY, K.; RADICH, H.; MAYNARD-CURRY, C.; CAPON, D. J.; TEDDER, I. F. Lymphocyte homing and leukocyte rolling and migration are impaired in L-selectin (CD62L) deficient mice. Immunity. v. 1, p. 247260, 1994

ARIFHODZIC, N. A.; MAHMOUD, F. F.; ABUL, H. T.; HAINES, D. D.; AL-OWAISAN, A. R.; AMMAR, I. M.; NOVOTNY, L.; WISE, J. A. Major lymphocyte populations and T-cell expression of ICAM-1 and L-selectin adhesion molecules in Kuwaitis with asthma and rhinitis. Arch. Environ. Occup. Health., v. 60, p. 243-7, 2005.

ARVIDSSON, M. B.; LÖWHAGEN, O.; RAK, S. Early and late phase asthmatic response in lower airways of cat-allergic asthmatic patients - a comparison between experimental and environmental allergen challenge. Allergy, v. 62, p. 488-94, 2007. BARNES, P. J. The cytokine network in asthma and chronic obstructive pulmonary disease. J. Clin. Invest., v. 118, p. 3546-56, 2008.

BARR, R. G.; WENTOWSKI, C. C.; GRODSTEIN, F.; SOMERS, S. C.; STAMPFER, M. J.; SCHWARTZ, J.; SPEIZER, F. E.; CAMARGO, C. A. Jr. Prospective study of postmenopausal hormone use and newly diagnosed asthma and chronic obstructive pulmonary disease. Arch. Intern. Med., v. 23, p. 379-86, 2004.

BARR, R. G.; WENTOWSKI, C. C.; GRODSTEIN, F.; SOMERS, S. C.; STAMPFER, M. J.; SCHWARTZ, J.; SPEIZER, F. E.; CAMARGO, C. A. Jr.. Prospective study of postmenopausal hormone use and newly diagnosed asthma and chronic obstructive pulmonary disease. Arch. Intern. Med., v. 164, p. 379-386, 2004.

De acordo com:

ASSOCIAÇÃO BRASILEIRA DE NORMAS TÉCNICAS. NBR 6023: Informação e documentação: referências: elaboração. Rio de Janeiro, 2002. 
BEVILACQUA, M. P.; NELSON, R. M. Selectins. J. Clin. Invest., v. 91, p. 379-387, 1993.

BEYNON, H.L.; GARBETT, N. D.; BARNES, P. J. Severe premenstrual exacerbations of asthma: effect of intramuscular progesterone. Lancet, v. 13, p. 2, 1988.

BONACCI, J. V.; SCHULIGA, M.; HARRIS, T.; STEWART, A. G. Collagen impairs glucocorticoid actions in airway smooth muscle through integrin signalling. Br. J. Pharmacol., v. 149, p. 365-73, 2006.

BONNER, J. R. The epidemiology and natural history of asthma. Clin. Chest Med., v. 5, p. 557-65, 1983.

BOUSQUET, J.; JEFFERY, P. K.; BUSSE, W. W.; JOHNSON, M.; VIGNOLA, A. M. Asthma from bronchoconstriction to airways inflammation and remodeling. Am. J. Respir. Crit. Care Med., v. 16, p. 1720-45, 2000.

BOUSQUET, J.; VAN CAUWENBERGE P. A critical appraisal of 'evidence-based medicine' in allergy and asthma. Allergy, v. 78, p. 12-20, 2004.

BRANNSTROM, M.; FRIDEN, B. E.; JASPER, M.; NORMAN, R. J. Variations in peripheral blood levels of immunoreactive tumor necrosis factor alpha (TNFalpha) throughout the menstrual cycle and secretion of TNFalpha from the human corpus luteum. Eur. J. Obstet. Gynecol. Reprod. Biol., v. 83, p. 213-7. 1999.

BURGESS, J. K. The role of the extracellular matrix and specific growth factors in the regulation of inflammation and remodelling in asthma. Pharmacol., v. 122, p. 19-29, 2009.

CALVANI, N.; TUCCI, M.; RICHARDS, H. B.; TARTAGLIA, P.; SILVESTRIS, F. Th1 cytokines in the pathogenesis of lupus nephritis: the role of IL-18. Autoimmun., v. 4, p. $542-8,2005$.

CARRILLO, D. T.; MARTINEZ, T. J. A.; CUMPLIDO, B. J. A. Different types of inflammatory response. Arch. Bronconeumol., v. 42, p. 13-19, 2006.

CHHABRA, S. K. Premenstrual Asthma. Indian J. Chest Dis. Allied. Sci., v. 47, p. 109-116, 2005. 
CHHABRA, S. K.; KAUSHIK, S. Validation of the asthma quality of life questionnaire (AQLQ-UK English version) in Indian asthmatic subjects. Indian. J. Chest Dis. Allied. Sci, v. 47, p. 167-73, 2005.

CHO J. Y.; MILLER M. BAEK K. J.; HAN J. W.; NAYAR J.; LEE S. Y.; MCELWAIN K.; MCELWAIN S.; FRIEDMAN S.; BROIDE D. H.; Inhibition of airway remodeling in IL-5 deficient mice. J. Clin. Invest., v. 113, p. 551-560, 2004

COHEN, P. G. and HOLBROOK, J. M. Postmenopausal asthma: the estradiol 11 beta-hydroxysteroid dehydrogenase connection. Arch. Intern. Med., v. 13, p. 164, 2004.

COHN, L.; HERRICK, C.; NIU, N.; HOMER, R. J.; BOTTOMLY, K. IL-4 Promotes airway eosinophilia by suppressing IFN-g production: defining a novel role for IFN-g in the regulation of allergic airway inflammation. Journal of Immunology., v. 166, p. 2760-7, 2001.

CORTELING, R.; TRIFILIEFF, A. Gender comparison in a murine model of allergendriven airway inflammation and the response to budesonide treatment. B. M. C. Pharmacol., v. 15, p. 4, 2004.

DAVIS, G. E.; BAYLESS, K. J.; DAVIS, M. J.; MEININGER, G. A. Regulation of tissue injury responses by the exposure of matricryptic sites within extracellular matrixmolecules. Am. J. Pathol., v. 156, p. 1489-98, 2000.

DE MONCHY, J. G.; KAUFFMAN, H. F.; VENGE, P.; KOËTER, G. H.; JANSEN, H. M.; SLUITER, H. J.; DE VRIES, K. Bronchoalveolar eosinophilia during allergeninduced late asthmatic reactions. Am. Rev. Respir. Dis., v. 131, p. 373-76, 1985.

DEVALIA, J. L. and DAVIES, R. J. Airway epithelial cells and mediators of inflammation. Respir. Med., v. 87, p. 405-8, 1993.

DEVALIA, J. L.; CAMPBELL, A. M.; SAPSFORD, R. J.; RUNSZNAK, C.; QUINT, D.; GODDARD, P.; BOUSQUET, J.; DAVIES, R. J. Effect of nitrogen dioxide on synthesis of inflammatory cytokines expressed by human bronchial epithelial cells in vitro. Am. J. Resp. Cell Mol. Biol., v. 9, p. 271-8, 1993.

DIMITROPOULOU, C.; DRAKOPANAGIOTAKIS, F.; CHATTERJEE, A.; SNEAD, C.; CATRAVAS, J. D. Estrogen replacement therapy prevents airway dysfunction in a murine model of allergen-induced asthma. Lung, v. 187, p. 116-27, 2009. 
Disponível em: http://www. datasus.gov.br, acesso em: 01set. 2007.

DOHERTY, T. and BROIDE, D. Cytokines and growth factors in airway remodeling in asthma.Curr. Opin. Immunol., v. 19, p. 676-80, 2007.

DONALDSON, C.; EDER, S.; BAKER, C.; ARONOVITZ, M. J.; WEISS, A. D.; HALLPORTER, M.; ACKERMAN, A.; KARAS, R. H.; MOLKENTIN, J. D.; PATTEN, R. D. Estrogen attenuates left ventricular and cardiomyocyte hypertrophy by an estrogen receptor-dependent pathway that increases calcineurin degradation. Circ. Res., v. 104, p. 265-75, 2009.

DORE, M.; KORTHUIS, R. J.; GRANGER, D. N.; ENTMAN, M. L.; SMITH, C. W. Pselectin mediates spontaneous leukocyte rolling in vivo. Blood, v. 82, p. 1308-16, 1993.

DUNNIL, M. S. The Pathology of asthma, with especial reference to changes in the bronchial mucosa. Clin. J. Pathol., v. 13, p. 27-33, 1960.

ENSOM, M. H. H.; CHONG, G.; BEAUDIN, B.; BAI, T. R. Estradiol in Severe Asthma with Premenstrual Worsening. Ann of Pharmacol., v. 37, p. 1610-3, 2003.

FAAS, M.; BOUMAN, A.; MOES, H.; HEINEMAN, M. J.; LEIJ, L. D.; SCHUILING, G. The immune response during the luteal phase of the ovarian cycle: a Th2-type response? Fertil. Steril., v. 74, p.1008-13, 2000.

FISH, E. N. The X-files in immunity: sex-based differences predispose immune responses. Nat Rev Immunol., v. 8, p. 737-44, 2008.

FODA, H. D.; GEORGE, S.; ROLLO, E.; DREWS, M.; CONNER, C.; CAO, J. Regulation of gelatinases in human airway smooth muscle cells: mechanism of progelatinase A activation. Am. J. Physiol., v. 277, p. 174-82, 1999.

FRANK R. the Hormonal Causes of Premenstrual Asthma. Arch. Neurol. Psychiatry, v. 26, p. 1053, 1931.

GALLI, E.; GIANNI, S.; AURICCHIO, G.; BRUNETTI, E.; MANCINO, G.; ROSSI, P. Atopic dermatitis and asthma. Allergy Asthma Proc., v. 28, p. 540-3, 2007. 
GALLI, S. J.; TSAI, M.; PILIPONSKY, A. M.; The development of allergic inflammation. Nature, v. 24; p. 445-54, 2008.

GEHLBACH, B.; KRESS, J. P.; KAHN, J.; DERUITER, C.; POHLMAN, A.; HALL, J. Correlates of prolonged hospitalization in inner-city ICU patients receiving noninvasive and invasive positive pressure ventilation for status asthmaticus. Chest , v. 122, p. 1709-1714, 2002.

GIL, F. R. and LAUZON, A. M.; Smooth muscle molecular mechanics in airway hyperresponsiveness and asthma. Can. J. Physiol. Pharmacol., v. 85, p. 133-40, 2007.

GOMEZ REAL, F.; SVANES, C.; BJORNSSON, E. H.; FRANKLIN, K. A.; GISLASON, D.; GISLASON, T.; GULSVIK, A.; JANSON, C.; JOGI, R.; KISERUD, T.; Hormone replacement therapy, body mass index and asthma in perimenopausal women: a cross sectional survey. Thorax, v. 61, p. 34-40, 2006.

GRAVES, B. J.; CROWTHER, R. L.; CHANDRAN, C.; RUMBERGER, J. M.; LI, S.; HUANG, K.-S.; PRESKY, D. H.; FAMILLETTI, P.C.; WOLITZKY, B. A.; BUMS, D. K. Insight into $E$-selectiWligand interaction from the crystal structure and mutagenesis of the lec/EGF domains. Nature, v. 367, p. 532-538, 1994.

GREENLEE, K. J.; WERB, Z.; KHERADMAND, F. Matrix metalloproteinases in lung: multiple, multifarious, and multifaceted. Physiol., v. 87, p. 69-98, 2007.

HAGGERTY, C. L.; NESS, R. B.; KELSEY, S.; WATERER, G. W. The impact of estrogen and progesterone on asthma. Ann. Allergy Asthma Immunol., v. 90, p. 284-91, 2003.

HAMANO, N.; TERADA, N.; MAESAKO, K. Effect of female hormones on the production of IL-4 and IL-13 from peripheral blood mononuclear cells. Acta Otolaryngol. Suppl., v. 537, p. 27-31, 1998.

HAMID, Q.; TULIC', M. K.; LIU, M. C.; MOQBEL, R. Inflammatory cells in asthma: mechanisms and implications for therapy. J. Allergy Clin. Immunol., v. 111, p. S5S12, 2003.

HAYWARD, C. S.; KELLY, R. P.; COLLINS, P. The roles of gender, the menopause and hormone replacement on cardiovascular function. Cardiovasc. Res., v. 46, p. 28-49, 2000. 
HELLINGS, P. W.; VANDEKERCKHOVE, P.; CLAEYS, R.; BILLEN, J.; KASRAN, A.; CEUPPENS, J. L. Progesterone increases airway eosinophilia and hyperresponsiveness in a murine model of allergic asthma. Clin. Exp. Allergy, v. 33, p. 1457-63, 2003.

HELLINS, P. W.; VANDERKERCKHOVET, P.; CLAEYST,R.; BILLEN, J.; KASRAN, A.; CEUPPENS, J. L. Progesterone increase airway eosinophilia and hyperresponsiveness in a murine model of allergic asthma. Clin. Exp. Allergy., v. 33, p. 1457-63, 2003.

HENDERSON, N.; MARKWICK, L. J.; ELSHAW, S.R.; FREYER, A. M.; KNOX, A. J.; JOHNSON, S. R. Collagen I and thrombin activate MMP-2 by MMP-14-dependent and independent pathways: implications for airway smooth muscle migration. Am. J. Physiol. Lung. Cell. Mol. Physiol., v. 292, p. L1030-8, 2007.

HOGG, J. C. The pathology of asthma. U. B. C Pulmonary Research Laboratory, v. 105, p. 735-45, 1997.

HOLGATE, S. T. Pathogenesis of asthma. Clin. Exp. Allergy., v. 38, p. 872-97, 2008.

HUGHES, G. C.; CLARK, E. A. Regulation of dendritic cells by female sex steroids: Relevance to immunity and autoimmunity. Autoimmunity, v. 40, p. 470-81, 2007. human corpus luteum. Eur. J. Obstet. Gynecol. Reprod. Biol., v. 83, p. 213-7. 1999.

JEFFERY, P. K. Remodeling in asthma and chronic obstructive lung disease. Am. J. Respir. Crit. Care Med., v. 164, p. S28-S38, 2001.

KAY, A. B. Allergy and allergic diseases. First of two parts. N. Engl. J. Med., v. 344, p. 30-7, 2001.

KHOR, Y. H.; FELTIS, B. N.; REID, D. W.; WARD, C.; JOHNS, D. P.; WOODBAKER, R.; WALTERS, E. H. Airway cell and cytokine changes in early asthma deterioration after inhaled corticosteroid reduction. Clin. Exp. Allergy., v. 37, p. 1189-98, 2007.

KIM, S. J.; KIM, C. H.; AHN, J. H.; KIM, M. S.; KIM, S. C.; LEE, S. Y.; KWON, S. S.; KIM, Y. K.; KIM, K. H.; MOON, H. S.; SONG, J. S.; PARK, S. H. Time Sequence of Airway Remodeling in a Mouse Model of Chronic Asthma: the Relation with Airway Hiperrespositiveness. J. Korean Med., v. 22, p. 183-91, 2007. 
KIPS, J. C. Citokines in Asthma. Eur. Respir. J., v. 34, p. 24S-33S, 2001.

KIPS,J. C.; TOURNOY, K. G.; PAUWELS, R. A.; New anti-asthma therapies: suppression of the effect of interleukin (IL)-4 and IL-5. Eur. Respir., v. 17, p. 499506, 2001.

KNIGHT, D. Increased permeability of asthmatic epithelial cells to pollutants. Does this mean that they are intrinsically abnormal? Clin. Exp. Allergy., v. 32, p. 1263-5, 2002.

KOBAYASHI, Y.; MATSUMOTO, M.; KOTANI, M.; MAKINO, T. Possible involvement of matrix metalloproteinase-9 in Langerhans cell migration and maturation. $J$. Immunol., v. 163, p. 5989-93, 1999.

$\mathrm{KOCH}$, M.; WITZENRATH, M.; REUTER, C. Role of local pulmonary IFN-gamma expression in murine allergic airway inflammation. Am. Respir. Cell Mol. Biol., v. 35, p. 211-9, 2006.

KUMAR, R. K.; WEBB D. C.; HERBERT, C.; FOSTER, P. S. Interferon-gamma as a possible target in chronic asthma. Inflamm. Allergy Drug Targets, v. 5, p. 253-6, 2006.

KUYPER, L. M.; PARÉ, P. D.; HOGG, J. C.; LAMBERT, R. K.; IONESCU, D.; WOODS, R.; BAI, T. R. Characterization of airway plugging in fatal asthma. J. Med., v. 115, p. 6-11, 2003.

LAITINEN, A.; ALTRAJA, A.; KÄMPE, M.; LINDEN, M.; VIRTANEN, I.; LAITINEN, L. A. Tenascin is increased in airway basement membrane of asthmatics and decreased by an inhaled steroid. Am. J. Respir. Crit. Care Med., v. 156, p. 951-8, 1997.

LAMOOREAUX, W. J.; FITZGERALD, M. E. C.; REINER, A.; HATY, K. A.; CHARLES, S. T. Vascular endothelial growth factor increase release of gelatinase $A$ and decrease release of tissue inhibitor of metalloproteinases by microvascular endothelial cells in vitro. Microvasc., v. 55, p. 29-42, 1998.

LANGE, P.; PARNER, J.; PRESCOTT, E.; ULRIK, C.; VESTBO, J. Exogenous female sex steroid hormones and risk of asthma and asthma-like symptoms:

a cross sectional study of the general population. Thorax, v. 56, p. 613-616, 2001. 
LEE, J. H.; HASELKORN, T.; CHIPPS, B. E.; MILLER, D.P.; WENZEL, S.E.; Gender differences in IgE-mediated allergic asthma in the epidemiology and natural history of asthma: Outcomes and Treatment Regimens. J. Asthma, v. 43, p. 179-184, 2006.

LEY, K. The role of selectins in inflammation and disease. Trends. Mol. Med., v. 9, p. 263-8, 2003.

LIEBERMAN, D.; KOPERNIK, G.; PORATH, A.; LAZER, S.; HEIMER, D. Sub-clinical worsening of bronchial asthma during estrogen replacement therapy in asthmatic post-menopausal women. Maturitas, v. 21, p. 153-7, 1995.

LIGEIRO, A. P.; OLIVEIRA, F. R. M.; DA SILVA, Z. L.; BOELLI,P.; TAVARES, W. L. Regulation of allergic lung inflammation in rats: interation beteween estradiol and corticosterone. Neuroimmunomodulation, v. 11, p. 20-27, 2004.

LIN, R. Y.; REHMAN, A. Clinical characteristics of adult asthmatics requiring intubation. J. Med. v. 26, p. 261-277, 1995.

MAGNAN, A. O.; MÉLY, L. G.; CAMILLA, C. A.; BADIER, M. M.; MONTER JULIAN, F. A. GUILLOT, C. M.; CASANO, B B.; PRATO, S. J.; FERT, V.; BONGRAND, P.; VERVLOET, D. Assessment of the Th1/Th2 paradigm in whole blood in atopy and asthma. Increased IFN-gamma-producing CD8(+) T cells in asthma. Am. J. Respir. Crit. Care Med., v. 161, p. 1790-6, 2000.

MANTHOUS, C. A. Gender and status asthmaticus. J. Asthma. v. 40, p. 763-767, 2003.

MARIN, M. G. Low-dose methotrexate spares steroid usage insteroid-dependent asthmatic patients: a meta-analysis. Chest, v. 112, p. 29-33, 1997.

MAUAD, T.; BEL, E. H.; STERK, P. J. Asthma therapy and airway remodeling. J. Allergy Clin. Immunol., v. 120, p. 997-1009, 2007.

MCEVER, R. P. GMP-140, a platelet alpha-granule membrane protein, is also synthesized by vascular endothelial cells and is localized in Weibel-Palade bodies. $\mathbf{J}$. Clin. Invest., v. 84, p. 92-99, 1989.

MEHROTRA, A. K. and HENDERSON, W.R. The role of leukotrienes in airway remodeling. Curr. Mol. Med., v. 9, p. 383-91, 2009. 
MELGERT, B. N.; POSTMA, D. S.; KUIPERS, I.; GEERLINGS, M.; LUINGE, M. A.; VAN DER STRATE, B. W.; KERSTJENS, H.A.; TIMENS, W.; HYLKEMA, M. N. Female mice are more susceptible to the development of allergic airway inflammation than male mice. Clin. Exp. Allergy, v. 35, p. 1496-503, 2005.

METZGER, W. J.; RICHERSON, H. B.; WORDEN, K.; MONICK, M.; HUNNINGHAKE, G. W. Bronchoalveolar lavage ofallergic asthmatic patients following allergen bronchoprovocation. Chest., v. 89, p. 477-83, 1986.

MONIUSZKO, M.; BODZENTA-LUKASZYK, A.; KOWAL, K.; DABROWSKA, M. Bronchial macrophages in asthmatics reveal decreased CD16 expression and substantial levels of receptors for IL-10, but not IL-4 and IL-7. Folia Histochem Cytobiol., v. 45, p. 181-9, 2007.

MONTERO, V. M. T. New aspects on inflammation in allergic diseases. Allergol. Immunopathol., v. 34, p. 129-3, 2006.

MOSMANN, T.R. and SAD, S. The expanding universe of T-cell subsets: Th1, Th2 and more. Immunol. Today., v. 17, p. 138-46, 1996.

MOYNIHAN, B. J.; TOLLOCZKO, B.; EL BASSAM, S.; FERRARO, P.; MICHOUD, M. C.; MARTIN, J. G.; LABERGE, S. IFN-gamma, IL-4 and IL-13 modulate responsiveness of human airway smooth muscle cells to IL-13. Respir. Res., v. 30, p. 84, 2008.

MURPHY, V. E.; CLIFTON, V. L.; GIBSON, P. G. Asthma exacerbations during pregnancy: incidence and association with adverse pregnancy outcomes. Thorax, v. 61, p. 169-76, 2006.

NADI, E.; HAJILOOI, M.; ZERAATI, F.; ANSARI, M.; TAVANA, S.; HASHEMI, S. H.; RAFIEI, A. E-selectin S128R polymorphism leads to severe asthma. Iran. J. Allergy Asthma Immunol., v. 6, p. 49-57, 2007.

NAKASATO, H.; OHRUI, T.; SEKIZAWA, K.; MATSUI, T.; YAMAYA, M.; TAMURA, G.; SASAKI, H. Prevention of severe premenstrual asthma attacks by leukotriene receptor antagonist. J. Allergy Clin. Immunol., v. 104, p. 585-8, 1999.

NGOC, P. L.; GOLD, D. R.; TZIANABOS, A. O.; WEISS, S. T.; CELEDÓN, J. Cytokines, allergy, and asthma. Curr. Opin. Allergy Clin. Immunol., v. 5, p. 161-6, 2005. 
NGUYEN, M.; ARKELL, J.; JACKSON, C. J. Active and tissue inhibitor of matrix metalloproteinase-free gelatinase $B$ accumulates within human microvascular endothelial vesicles. J. Biol. Chem., v. 273, p. 5400-04, 1998.

OKADA, S.; KITA, H.; GEORGE, T. J.; GLEICH, G. J.; LEIFERMAN, K. M. Migration of eosinophils through basement membrane components in vitro: role of matrix metalloproteinase-9. Am. J. Respir. Cell Mol. Biol., v. 17, p. 519-28, 1997.

OKAYAMA, Y.; R A, C.; SAITO, H. Role of mast cells in airway remodeling. Curr. Opin. Immunol., v. 28, p. 40-6, 2007.

ORDOÑEZ, C. L.; KHASHAYAR, R.; WONG, H. H.; FERRANDO, R.; WU, R; HYDE, D. M.; HOTCHKISS, J. A.; ZHANG, Y.; NOVIKOV, A.; DOLGANOV, G.; FAHY, J. V. Mild and moderate asthma is associated with airway goblet cell hyperplasia and abnormalities in mucin gene expression. Am. J. Respir. Crit. Care Med., v. 163, p. 517-23, 2001.

PITCHFORD, S. C.; MOMI, S.; GIANNINI, S.; CASALI. L.; SPINA, D.; PAGE, C. P.; GRESELE P. Platelet P-selectin is required for pulmonary eosinophil and lymphocyte recruitment in a murine model of allergic inflammation. Blood, v. 1, p. 105, p. 2074$81,2005$.

RAINES, E. W.; KOYAMA, H.; CARRAGHER, N. O. The extracellular matrix dynamically regulates smooth muscle cell responsiveness to PDGF. Ann. N. Y. Acad., v. 902, p. 39-51, 2000.

RAO, S.; RAJU, P.; SMINA, M.; UPADYA, A.; AMOATENG-ADJEPONG, Y.; receiving noninvasive and invasive positive pressure ventilation for status asthmaticus. Chest, v. 122, p. 1709-1714, 2002.

REDMOND, A. M.; JAMES, A. W.; NOLAN, S. H.; SELF, T. H. Premenstrual asthma: emphasis on drug therapy options. J. Asthma., v. 41, p. 687-93, 2004.

REED, C. E. Basic mechanisms of asthma. Role of inflammation.Chest., v. 94, p. 175-7,1988.

REED, C. E. The natural history of asthma. J. Allergy Clin. Immuno., v. 118, p. 5438; 2006. 
REID, L. M. The presence or absence of bronchial mucus in fatal asthma. J. Allergy Clin. Immunol., v. 80, p. 415-6, 1987.

REINHARDT, A. K.; BOTTOMS, S. E.; LAURENT, G. J.; MCANULTY, R. J. Quantification of collagen and proteoglycan deposition in a murine model of airway remodelling. Respir. Res., v. 8, p. 6-30, 2005.

RIFFO-VASQUEZ, Y.; OLIVEIRA, A. P.; PAGE, C. P.; SPINA, D.; TAVARES DE LIMA, W. Role of Sex Hormones in Allergic Inflammation in Mice. Clinical and Experimental Allergy., v. 37, p. 459-470, 2007.

ROBERTS, C. R. and BURKE, A. K. Remodelling of the extracellular matrix in asthma: proteoglycan synthesis and degradation. Can. Respir. J., v. 5, p. 48-50, 1998.

ROBINSON, D. S. The role of the mast cell in asthma: induction of airway hyperresponsiveness by interaction with smooth muscle? J. Allergy Clin. Immunol., v. 114, p. 58-65, 2004.

ROCHLITZER, S.; NASSENSTEIN, C.; BRAUN, A. The ontribution of neutrophins to the pathogenesis of allergic asthma. Biochem. Soc. Trans., v. 34, p. 4, 2006.

ROMAGNANI, S. Regulation of the T cell response. Clin. Exp. Allergy, v. 36, p. 1357-66, 2006.

ROSE, M. C.; VOYNOW, J. A. Respiratory tract mucin genes and mucin glycoproteins in health and disease. Physiol., v. 86, p. 245-278, 2006.

ROSSI, B. and CONSTANTIN, G. Anti-selectin therapy for the treatment of inflammatory diseases. Inflamm. Allergy Drug Targets, v. 7, p. 85-93, 2008.

ROWE, B. H.; VOAKLANDER, D. C.; WANG, D.; SENTHILSELVAN, A.; KLASSEN, T. P.; MARRIE, T. J.; ROSYCHUK, R. J. Asthma presentations by adults to emergency departments in Alberta, Canada: a large population-based study. Ches. v. 135, p. 57-65, 2009.

RUBIO RAVELO, L.; GAGO RODRIGUEZ, B.; ALMIRALL COLLAZO, J. J.; BELL HEREDIA, L.; FERNANDEZ, L. Comparative study of progesterone, estradiol and cortisol concentrations in asthmatic and non-asthmatic women. Allergol. Immunopathol., v. 16, p. 263-6. 1988. 
SACCO, O.; SILVESTRI, M.; SABATINI, F.; SALE, R.; DEFILIPPI, A. C.; ROSSI, G. A. Epithelial cells and fibroblasts: structural repair and remodelling in the airways. Pediatr. Respir. Review, v. 5, p. 35-40, 2004.

SCHATZ, M.; CLARK, S.; CAMARGO, C. A. Jr. Sex differences in the presentation and course of asthma hospitalizations. Chest, v. 129, p. 50-5, 2006.

SCHLEIMER, R. P.; KATO, A., KERN, R.; KUPERMAN, D.; AVILA, P. C. Epithelium: at the interface of innate and adaptive immune responses. J. Allergy Clin. Immunol., v. 120, p. 1279-84, 2007.

SHANNON, J.; ERNST, P.; YAMAUCHI, Y.; OLIVENSTEIN, R.; LEMIERE, C.; FOLEY, S.; CICORA, L.; LUDWIG, M.; HAMID, Q.; MARTIN, J. G. Differences in airway cytokine profile in severe asthma compared to moderate asthma. Chest, v. 133, p. 420-6, 2008.

SHIMURA, S.; ANDOH, Y.; HARAGUCHI, M.; SHIRATO, K. Continuity of airway goblet cells and intraluminal mucus in the airways of patients with bronchial asthma. Eur. Respir. J., v. 9, p. 1395-401, 1996.

SIROUX, V.; CURT, F.; ORYSZCZYN, M. P.; MACCARIO, J.; KAUFFMANN, F. Role of gender and hormone-related events on IgE, atopy, and eosinophils in

SKOBELOFF, E. M.; SPIVEY, W. H.; St CLAIR, S. S.; SCHOFFSTALL, J. M.; The influence of age and sex on asthma admissions. J. A. M. A., v. 268, p. 3437-3440, 1992.

SMITH, K.; WARHOLAK, T.; ARMSTRONG, E.; LEIB, M.; REHFELD, R.; MALONE, D. Evaluation of risk factors and health outcomes among persons with asthma. $\mathbf{J}$. Asth., v. 46, p. 234-237, 2009.

SPERTINI, 0.; LUSCINSKAS, F. W.; KANSAS, C. S.; MUNRO, J. M.; GRIFFIN, J. D.; GIMBRONE JR, M. A.; TEDDER, F. Leukocyte adhesion molecule-I (LAM-i. Lselectin) interacts with an inducible endothelial cell ligand to support leukocyte adhesion. Immunol., v. 147, p. 2565-73, 1991.

SPORNITZ, U. M.; SOCIN, C, D.; DRAVID, A. A. Estrous stage determination in rats by means of scanning electron microscopic images of uterine surface epithelium. Anat. Rec., v. 254, p. 116-26, 1999. 
STANFORD, K. I.; MICKLEBOROUGH, T. D.; RAY, S.; LINDLEY, M. R.; KOCEJA, D. M.; STAGER, J. M. Influence of menstrual cycle phase on pulmonary function in asthmatic athletes. Eur. J. Appl. Physiol., v. 96, p. 703-710, 2006.

SUBRAMANIAM, M.; KOEDAM, J. A.; WAGNER, D. D. Divergent fates of P- and Eselectins after their expression on the plasma membrane. Mol. Biol. Cell., v. 4, p. 791-801, 1993.

TANG, M. L. and FISCUS, L. C. Important roles for L-selectin and ICAM-1 in the development of allergic airway inflammation in asthma. Pulm. Pharmacol., v. 14, p. 203-10, 2001.

TANG, S. K. Premenstrual Asthma. Drugs, v. 61, p. 2079-2086, 2001.

TEDDER, T. F.; STEEBER D. A.; CHEN A.; ENGEL P. The selectins: vascular adhesion molecules. Faseb. J., v. 9, p. 866-73, 1995.

TEMPRANO, J. and MANNINO, D. M. The effect of sex on asthma control from the National Asthma Survey. J. Allergy Clin. Immunol., v. 123, p. 854-860, 2009.

the epidemiological study on the genetics and environment of asthma, bronchial hyperresponsiveness and atopy. J. Allergy Clin. Immunol., v. 114, p. 491-498, 2004.

TLIBA, O.; AMRANI, Y.; PANETTIERI, R. A. Jr. Is airway smooth muscle the "missing link" modulating airway inflammation in asthma? Chest, v. 133, p. 236-42, 1998.

TROISI, R. J.; SPEIZER, F. E.; WILLETT, W. C.; TRICHOPOULOS, D.; ROSNER, B. Menopause, postmenopausal estrogen preparations, and the risk of adultonset asthma: a prospective cohort study. Am. J. Respir. Crit. Care Med., v. 152, p. 11831188, 1995.

TSAI, M.; PILIPONSKY, A. M.; GALLI, S. J. The development of allergic inflammation., Nature, v. 24, p. 445-54, 2008.

TSAI, T. C.; LU, J. H.; CHEN, S. J.; TANG, R. B. Soluble interleukin-10 and transforming growth factor-beta in children with acute exacerbation of allergic asthma. J. Asthma, v. 46, p. 21-4, 2009.

ULBRICH, H.; ERIKSSON, E. E.; LINDBOM, L. Leukocyte and endothelial cell adhesion molecules as targets for therapeutic interventions in inflammatory disease. Trends Pharmacol., v. 24, p. 640-7, 2003. 
VAN OOSTERHOUT, A. J. and BLOKSMA, N. Regulatory T-lymphocytes in asthma. Eur. Respir. J., v. 26, p. 918-32, 2005.

VERGNENEÁGRE, A; ANTONINI, M. T.; BONNAUD, F.; MELLONI, B.; MIGNONAT, G.; BOUSQUET, J. Comparison between late onset and childhood asthma. Allergol. Immunopathol., v. 20, p. 190-6, 1992.

VRIEZE, A.; POSTMA,D. S.; KERSTJENS, H. A. M. Perimenstrual asthma: A syndrome without known cause or cure. J. Allergy Clin. Immunol., v. 112, p. 27182, 2003.

WARD, C., PAIS, M., BISH, R., FELTIS, B., JOHNS D., WALTERS, E.H. Airway inflammation, basement membrane thickening and bronchial hyperrespositiveness in asthma. Torax, v. 57, p. 309-16, 2002.

WEATHINGTON, N. M.; VAN HOUWELINGEN, A. H.; NOERAGER, B. D.; JACKSON, P. L.; KRANEVELD, A. D.; GALIN, F. S.; FOLKERTS, G.; NIJKAMP, F. P.; BLALOCK, J. E. A novel peptide CXCR ligand derived from extracellular matrix degradation during airway inflammation. Nat. Med., v. 12, p. 317-23, 2006.

WENNER, C. A.; GÜLER, M. L.; MACATONIA, S. E.; O'GARRA, A.; MURPHY, K. M. Roles of IFN-gamma and IFN-alpha in IL-12-induced T helper cell-1 development. J. Immunol., v. 15, p. 1442-7, 1996.

WILLS-KARP, M. Interleukin-13 in asthma pathogenesis., Immunol., v. 202, p. 175190, 2004.

WILSON, J. W. and LI, X. The measurement of reticular basement membrane and submucosal collagen in the asthmatic airway. Clin. Exp. Allergy, v. 27, p. 363-71, 1997.

WOODFOLK J. A. Cytokines as a therapeutic target for allergic diseases: a complex picture. Curr. Pharm., v. 12, p. 2349-63, 2006.

WOODSIDE, D. G. and VANDERSLICE, P. Cell adhesion antagonists: therapeutic potential in asthma and chronic obstructive pulmonary disease. Bio Drugs, v. 22, p. 85-100, 2008.

WYNN, T. A. IL-13 effector functions. Annu. Rev. Immunol., v. 21, p. 425-56, 2003. 
XIE, S.; ISSA, R.; SUKKAR, M.B.; OLTMANNS, U.; BHAVSAR, P.K.; PAPI, A. Induction and regulation of matrix metalloproteinase-12 in human airway smooth muscle cells. Respir. Res., v. 6, p. 148, 2005.

YANG, G.; LI, L.; EMMEL, E.; PETLEY, T.; GILES-KOMAR, J.; RAFFERTY, P.; LAKSHMINARAYANAN, M.; GRISWOLD, D. E.; BUGELSKI, P. J.; DAS, A. M. Therapeutic Dosing With Anti Interleukin-13 Monoclonal Antibody Inhibits Asthma Progression in Mice. J. Pharmacol. Exp., v. 313, p. 8-15, 2005.

YANG, M,; HOGAN, S. P.; HENRY, P. J.; MATTHAEI, K. I.; MCKENZIE, A. N.; YOUNG, I. G. Interleukin-13 mediates airways hyperreactivity through the IL-4 receptor-alpha chain and STAT-6 independently of IL-5 and eotaxin. Am. J. Respir. Cell. Mol. Biol., v. 25, p. 522-30, 2001.

YING, S.; ZHANG, G.; ZHAO, J. How much do we know about atopic asthma: where are we now. Cell. Mol. Immuno., v. 3, p. 321-332, 2006.

YSSEL, H. and GROUX H.; Characterization of T cell subpopulations involved in the phatogenesis of asthma and allergic disease. Int. Arch. Allergy Immunol., v. 121, p. 10-8, 2000.

ZHAO, X. J.; MCKERR, G.; DONG, Z.; HIGGINS, C. A.; CARSON, J.; YANG, Z. Q. Expression of oestrogen and progesterone receptors by mast cells alone, but not lymphocytes, macrophages or other immune cells in human upper airways. Thorax, v. 56, p. 205-11, 2001.

ZHOU, X.; HU, H.; HUYNH, M. L.; KOTARU, C.; BALZAR, S.; TRUDEAU, J. B.; WENZEL, S. E. Mechanisms of tissue inhibitor of metalloproteinase 1 augmentation by IL-13 on TGF-beta1-stimulated primary human fibroblasts. J. Allergy Clin. Immunol. v. 119, p. 1388-97, 2007.

ZIAIE, Z.; FAWZI, A.; BELLON, G.; MONBOISSE, J. C.; KEFALIDES, N. A.; A peptide of the alpha3 chain of type IV collagen protects basement membrane against damage by PMN. Biochem. Biophys. Res. Commun., v. 2, p. 261, p. 247-50, 1999. 